\title{
Long-term results of GH therapy in GH-deficient children treated before 1 year of age
}

\author{
Frédéric Huet, Jean-Claude Carel $^{1}$, Jean-Louis Nivelon and Jean-Louis Chaussain ${ }^{1}$ \\ Service de Pédiatrie 1, Hôpital d'Enfants, Dijon, France and ${ }^{1}$ Service d'Endocrinologie Pédiatrique, Hôpital Saint Vincent de Paul, Paris, France \\ (Correspondence should be addressed to F Huet, Service de Pédiatrie 1, Hôpital d'Enfants, CHR du Bocage, 21034 Dijon Cedex, France)
}

\begin{abstract}
Objectives: To evaluate the long-term effects of GH therapy in early diagnosed GH-deficient patients treated before 1 year of age.

Study design: We studied all 59 patients (33 males) recorded by Association France-Hypophyse and treated with $\mathrm{GH}(0.50 \pm 0.15 \mathrm{IU} / \mathrm{kg}$ (s.D.) per week) before 1 year of age. Clinical presentation and growth parameters under GH treatment were analyzed.

Results: Neonatal manifestations of hypopituitarism were frequent: hypoglycemia $(n=50)$, jaundice $(n=25)$ and micropenis $(n=17 / 33)$. Although birth length was moderately reduced $(-0.9 \pm 1.4)$, growth retardation at diagnosis $(5.8 \pm 3.8$ months) was severe $(-3.5 \pm 1.9$ standard deviation scores (SDS)). Fifty patients (85\%) had thyrotropin and/or corticotropin deficiency. After a mean duration of GH therapy of $8.0 \pm 3.6$ years, change in height SDS was $+3.11 \pm 2.06$ S.D., exceeding 4 SDS in 19 patients. Only 9 patients $(15 \%)$ did not reach a height of -2 s.D. for chronological age and 20 patients (34\%) exceeded their target height. Pretreatment height SDS was independently associated with total catch-up growth.

Conclusion: Conventional doses of $\mathrm{GH}$ allow normalization of height in patients with early GH deficiency and treatment.
\end{abstract}

European Journal of Endocrinology 140 29-34

\section{Introduction}

One of the objectives of growth hormone $(\mathrm{GH})$ therapy in GH-deficient (GHD) children is to obtain a final height within normal limits with respect to the genetic potential of an individual. Long-term results of this treatment are now becoming available and remain disappointing, with adult heights often 2 s.D. below the population's mean $(1-5)$.

The failure to normalize final height has been attributed to intermittent and/or low doses of GH (6). However, several other factors have been identified in multivariate analyses as influencing final outcome, including target height, height and bone age (BA) deficit at the start of treatment, height at the start of puberty $(4,5)$ and age at the onset of treatment, earlier treatment resulting in higher adult heights (3, 4, 7-9). These findings probably reflect a wide heterogeneity of the treated patients.

Patients with GHD in infancy provide an exceptional opportunity for evaluation of the effects of $\mathrm{GH}$ treatment. First, the diagnosis of GHD is rarely equivocal in this age group. Secondly, catch-up growth can occur without interference from pubertal maturation. Earlier reports have indicated favorable outcomes in GHD patients treated before the age of 5 years. However, the number of patients in these series was often small and the age range at initiation of treatment was broad with a mean of 3 years $(8-12)$. Two prospective studies $(13,14)$ recently reported early onset of GH treatment (mean 1.5 years of age) in GHD patients, allowing a rapid catch-up growth during the first year of treatment.

In this report, we present data on 59 children in whom diagnosis and initiation of $\mathrm{GH}$ treatment were made before the age of 1 year, with a mean follow-up of 8 years. This homogeneous population of patients diagnosed early in life constitutes a model of $\mathrm{GH}$ deprivation, allowing the evaluation of the effectiveness of suppletive therapy.

\section{Patients and methods}

In France, from 1973 onwards, the distribution of GH, initially extracted but later recombinant, has been organized nationwide under the medical control of Association France-Hypophyse, as previously described (3). All deliveries of $\mathrm{GH}$ were registered and data on treated children were recorded on standardized charts. This database allowed us to identify patients for the present report with the following criteria: (i) diagnosis of GHD with a maximum peak level of $\mathrm{GH}<10 \mathrm{ng} / \mathrm{ml}$ after two standard pharmacological stimulation tests; (ii) initiation of $\mathrm{GH}$ treatment before the age of 1 year 
between 1978 and 1992; (iii) known birth weight and length and height at start of treatment; and (iv) treatment for at least 3 years.

Fifty-nine patients meeting these criteria were selected among a total of 70 infants treated with $\mathrm{GH}$ before 1 year of age. The reasons for excluding 11 patients from this analysis were: lack of auxological data $(n=3)$, interruption of treatment $(n=5)$ and inclusion in a prospective protocol with high doses of GH $(n=4)$.

Patients with isolated GHD (IGHD) as well as patients with combined multiple pituitary deficiencies (MPD) were included. GH assays were performed by individual hospital laboratories. Thyroid and adrenal evaluations were performed to identify additional hormonal deficiencies. Gonadotropin secretion was not investigated because of the difficulty of excluding gonadotropin deficiency before 1 year of age.

A history of multiple or resistant neonatal hypoglycemia associated with only one GH stimulation test was in a few cases $(n=7)$ considered as sufficient to establish the diagnosis of GHD. Resistant neonatal hypoglycemia was defined as a glycemia below $40 \mathrm{mg} /$ $\mathrm{dl}$ in spite of intravenous glucose intakes during the first days of life.

We used French standards for height and weight (15) and Usher \& MacLean standards for birth height and weight (16). Target height was calculated as the mean of parental standard deviation scores (SDS), obtained from standards of their approximate generation (17). Delta height SDS, i.e. height SDS at a given time of treatment minus height SDS at baseline, were calculated for 1,2 and 3 years of GH treatment and at the time of last evaluation. BA was estimated by the Greulich \& Pyle method (18). Predictions of adult height were calculated at the last evaluation by the method of Bayley \& Pinneau (19).

Human pituitary GH extracts, and, from 1987 onwards, GH produced by recombinant DNA technology, were used. There were some changes in therapeutic patterns over the study period and variations around the mean pattern $(0.50 \pm 0.15 \mathrm{IU} / \mathrm{kg}$ (S.D.) per week, three to seven injections per week). Patients with MPD received hydrocortisone and/or L-thyroxine replacement as needed.

\section{Statistics}

The data are reported as the means \pm S.D. Stepwise multiple regression analysis was used to explore predictive factors of catch-up growth in response to $\mathrm{GH}$ therapy. Simple linear regression was performed to examine the relationship between delta height SDS observed after 1 year of GH therapy and further changes in SDS. In the auxological evaluation, the MannWhitney U test was used for differences between sex groups and between IGHD and MPD.

\section{Results \\ Initial characteristics of the patients}

Among the 59 patients included in this study, 33 (56\%) were males. Seven breech presentations $(12 \%)$ and 12 cesarean sections $(21 \%)$ were observed. There were signs of pituitary dysfunction seen in infancy in 53 patients (Table 1). Auxological and endocrine data at the time of diagnosis are shown in Fig. 1 and Table 2 respectively. Although birth length was normal (>-2 SDS) in $47 / 59$ patients, height was severely reduced at the time of diagnosis, corresponding to a mean loss of $2.6 \pm 1.7$ SDS between birth and time of diagnosis ( $5.8 \pm 3.8$ months). At diagnosis, 46 patients $(78 \%)$ had a height below -2 SDS and 24 patients (41\%) below -4 SDS. Forty-five patients $(76 \%)$ had thyrotropin deficiency, 38 (64\%) had corticotropin deficiency and only 10 had IGHD. Diagnosis was made earlier in male than in female patients $(4.6 \pm 3.4 \mathrm{vs}$ $6.8 \pm 3.9$ months, $P<0.02)$. In 26 patients $(44 \%)$, magnetic resonance imaging (MRI) of the pituitary region was performed and showed hypoplasia of the anterior pituitary $(n=10)$, the absence of pituitary stalk $(n=10)$ or a normal pituitary $(n=6)$. All the patients with abnormal MRI had MPD. Target height was within the normal population range in all but three patients.

\section{GH treatment}

GH-induced catch-up growth was dramatic during the first year of treatment and reduced during subsequent

Table 1 Clinical characteristics of the patients in the neonatal period (means \pm S.D. and ranges where appropriate).

\begin{tabular}{lccc}
\hline & Male $(n=33)$ & Female $(n=26)$ & Total $(n=59)$ \\
\hline Delivery (weeks) & $39.8 \pm 1.7$ & $40.0 \pm 1.5$ & $39.9 \pm 1.6$ \\
Hypoglycemia $(n)$ & $29(88 \%)$ & $21(81 \%)$ & $50(85 \%)$ \\
Convulsions $(n)$ & $8(24 \%)$ & $6(23 \%)$ & $14(24 \%)$ \\
Micropenis $(n)$ & $17(52 \%)$ & - & - \\
Jaundice $(n)$ & $18(55 \%)$ & $7(27 \%)$ & $25(42 \%)$ \\
Birth length (cm) & $48.8 \pm 3.0$ & $47.4 \pm 2.6$ & $48.2 \pm 2.6$ \\
Birth length (SDS) & $-0.8 \pm 1.4$ & $-1.1 \pm 1.3$ & $-0.9 \pm 1.4$ \\
& $(-5.5$ to +0.88$)$ & $(-3.7$ to +1.4$)$ & $(-5.5$ to +1.4$)$ \\
\hline
\end{tabular}


Figure 1 Height evolution during GH therapy. Error bars show S.D.

years (Figs 1 and 2). The mean duration of treatment at the time of this analysis was $8.0 \pm 3.6$ years (range 3.0 to 15.8 years). At last evaluation (Table 3, Figs 3 and 4), $20 / 54$ patients $(37 \%)$ had reached their target height SDS, 20/59 patients (34\%) had reached the mean height for their age and $50(85 \%)$ had a height $\geq-2$ SDS. Delta height SDS during treatment was $3.1 \pm 2.0$ SDS (range -3.7 to +6.0 ), exceeding 4 SDS in 19 patients. Current height SDS was significantly higher in boys than in girls $(P<0.03)$ and there was a nonsignificant trend for higher height gain in boys (3.5 vs 2.6 SDS). At last evaluation, bone maturation was significantly retarded over chronological age (CA) by a mean value of $1.1 \pm 1.0$ years $(P<0.005)$. Auxological data were similar in patients with IGHD and those with MPD.

Predicted adult height, calculated in 29 patients (age $11.5 \pm 2.8$ years, BA $10.4 \pm 2.7$ years, target height $-0.56 \pm 0.79$ SDS) was $-0.35 \pm 1.4$ SDS (range -3.3 to 2.7 SDS). Four patients had a predicted height below -2 SDS (from -2.1 to -3.3 ) and $21(73 \%) \geq 0$ SDS. At last examination, seven patients had clinical signs of spontaneous $(n=2)$ or induced $(n=5)$ puberty. Five girls and one boy had reached a mean final height of $-0.7 \pm 1.1$ SDS.

\section{Predictive variables of GH treatment results}

The following variables were evaluated for prediction of current catch-up growth expressed in SDS in a stepwise multiple regression model: birth length SDS, target height SDS, age at diagnosis, height SDS at the start of treatment, maximum stimulated plasma GH, sex, IGHD or MPD, GH substitution dose, number of injections per week, duration of treatment, catch-up growth during the first year and further changes in height SDS (between the end of the first year and current height). Only two variables independently influenced total height gain. First, height SDS at the onset of treatment (regression coefficient $-0.521,95 \%$ confidence interval -0.629 to $-0.413, P<0.0001)$. This result indicates that the most severely retarded infants at diagnosis had greater catch-up growth. Secondly, total height gain during the first year of treatment (regression coefficient $0.684,95 \%$ confidence interval 0.546 to 0.822 , $P<0.0001)$. However, first year catch-up growth represents $63 \pm 45 \%$ of total height gain, explaining this artifactual 'whole/part' correlation. In contrast, we found no correlation between delta height SDS observed during the first year of treatment and further changes in SDS by simple linear regression analysis.

Table 2 Auxological and biological data at diagnosis (means \pm S.D. and ranges where appropriate).

\begin{tabular}{lccc}
\hline & Male $(n=33)$ & Female $(n=26)$ & Total $(n=59)$ \\
\hline Age (months) & $4.6 \pm 3.4$ & $6.8 \pm 3.9^{*}$ & $5.8 \pm 3.8$ \\
& $(0.5$ to 10$)$ & $(0.3$ to 12$)$ & $(0.3$ to 12$)$ \\
Height $(\mathrm{cm})$ & $56.2 \pm 5.9$ & $57.4 \pm 6.5$ & $56.7 \pm 6.1$ \\
& $(45.3$ to 66.0$)$ & $(48.0$ to 74.5$)$ & $(45.3$ to 74.5$)$ \\
Height $(\mathrm{SDS})$ & $-3.4 \pm 1.9$ & $-3.6 \pm 2.0$ & $-3.5 \pm 1.9$ \\
& $(-7.0$ to +1.6$)$ & $(-6.4$ to +1.4$)$ & $(-7.0$ to +1.6$)$ \\
Maximum stimulated GH $(\mu \mathrm{g} / \mathrm{l})$ & $2.8 \pm 3.3$ & $1.6 \pm 1.8$ & $2.2 \pm 2.8$ \\
& $(0$ to 8.0$)$ & $(0$ to 6.2$)$ & $(0$ to 8.0$)$ \\
GHD $(n)$ & 6 & 3 & 9 \\
Thyrotropin deficiency $(n)$ & 25 & 20 & 45 \\
Corticotropin deficiency $(n)$ & 21 & 17 & 38
\end{tabular}

${ }^{*} P<0.05$ when compared with male group. 


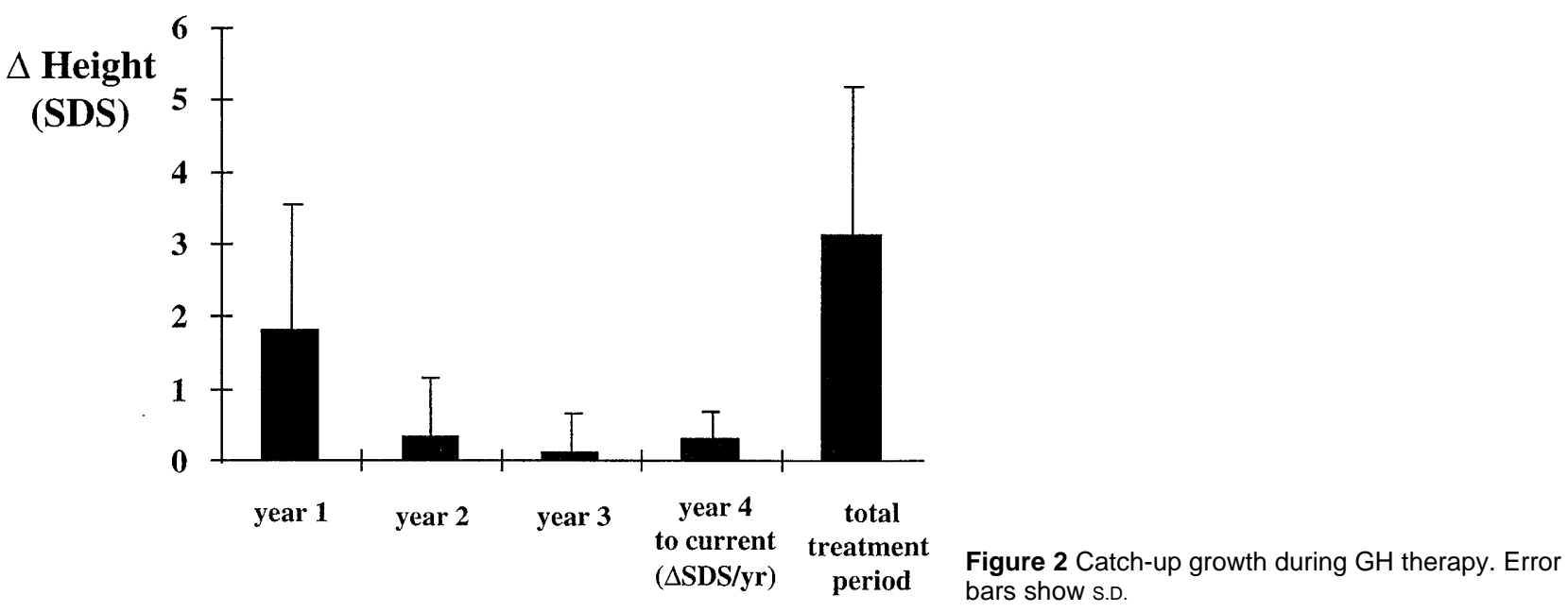

In simple linear regression, height SDS at onset of treatment was inversely correlated both with first year catch-up growth $(r=0.48, P<0.0001)$ and with further changes in height SDS $(r=0.40, P=0.0013)$, suggesting that the predictive influence of height SDS at onset of treatment was not the result of a regression towards the mean effect. In addition, the correlation between first year catch-up growth and height SDS at onset of treatment persisted after exclusion of patients with initially normal height $(n=46, \quad r=0.40$, $P=0.05)$.

\section{Discussion}

In these 59 patients with early onset GHD, GH treatment, initiated before 1 year of age, allowed a complete catch-up growth since, at the time of last follow-up, height was greater than target height. Our study confirms the importance of early diagnosis of GHD and the relatively unique pattern of response to treatment in this age range.

Clinical manifestations of neonatal hypopituitarism were frequent, with neonatal hypoglycemia in $85 \%$ of patients and seizures in $25 \%(20,21)$. There was a substantial delay between these neonatal symptoms and the diagnosis (age $5.8 \pm 3.8$ months), similar to that in previous reports $(22,23)$. The presence of a microgenitalism may have resulted in an earlier diagnosis in boys.

The striking growth deficit observed between birth and diagnosis $(-2.6 \pm 1.7$ SDS in 6 months $)$ indicates the crucial role of $\mathrm{GH}$ in early postnatal growth $(24$, 25). Similarly, Gluckman et al. (26) reported in 52 GHD patients an increasing frequency of height $\geq-2$ SDS with age: $21 \%$ at birth, $70 \%$ at 6 months and $91 \%$ at 12 months. In our patients as well as in other reports

Table 3 Current auxological data (means \pm S.D. and ranges).

\begin{tabular}{lccc}
\hline & Male $(n=33)$ & Female $(n=26)$ & Total $(n=59)$ \\
\hline CA (years) & $8.2 \pm 3.2$ & $8.7 \pm 4.3$ & $8.5 \pm 3.7$ \\
& $(3.4$ to 15.4$)$ & $(3.4$ to 16.2$)$ & $(3.4$ to 16.2$)$ \\
Duration of treatment (years) & $7.8 \pm 3.1$ & $8.2 \pm 4.1$ & $8.0 \pm 3.6$ \\
& $(3.0$ to 15.2$)$ & $(3.0$ to 15.8$)$ & $(3.0$ to 15.8$)$ \\
Current height (SDS) & $0.03 \pm 1.6$ & $-1.0 \pm 1.3^{*}$ & $-0.4 \pm 1.5$ \\
& $(-2.6$ to +6.0$)$ & $(-3.4$ to +1.1$)$ & $(-3.4$ to +6.0$)$ \\
Delta height SDS & $3.5 \pm 2.1$ & $2.6 \pm 2.0$ & $3.1 \pm 2.1$ \\
& $(-3.7$ to +7.0$)$ & $(-1.7$ to +6.2$)$ & $(-3.7$ to +7.0$)$ \\
Target height (SDS) & $-0.5 \pm 1.4$ & $-0.9 \pm 1.7$ & $-0.7 \pm 1.5$ \\
& $(-6.6$ to +1.0$)$ & $(-7.7$ to +0.9$)$ & $(-7.7$ to +1.0$)$ \\
Predicted height (SDS) & $0.4 \pm 1.2$ & $-1.0 \pm 1.7^{*}$ & $-0.3 \pm 1.4$ \\
& $(-0.8$ to +2.2$)$ & $(-2.5$ to +2.7$)$ & $(-3.3$ to +2.7$)$ \\
BA/CA & $0.88 \pm 0.14$ & $0.82 \pm 0.16$ & $0.85 \pm 0.15$ \\
& $(0.5$ to 1.1$)$ & $(0.5$ to 1.1$)$ & $(0.5$ to 1.1$)$ \\
\hline
\end{tabular}

${ }^{*} P<0.05$ when compared with male group.

$\mathrm{CA}$, chronological age. 
Figure 3 Initial and current data. ${ }^{*} P<0.05$ when the female group is compared with the male. Error bars show S.D.

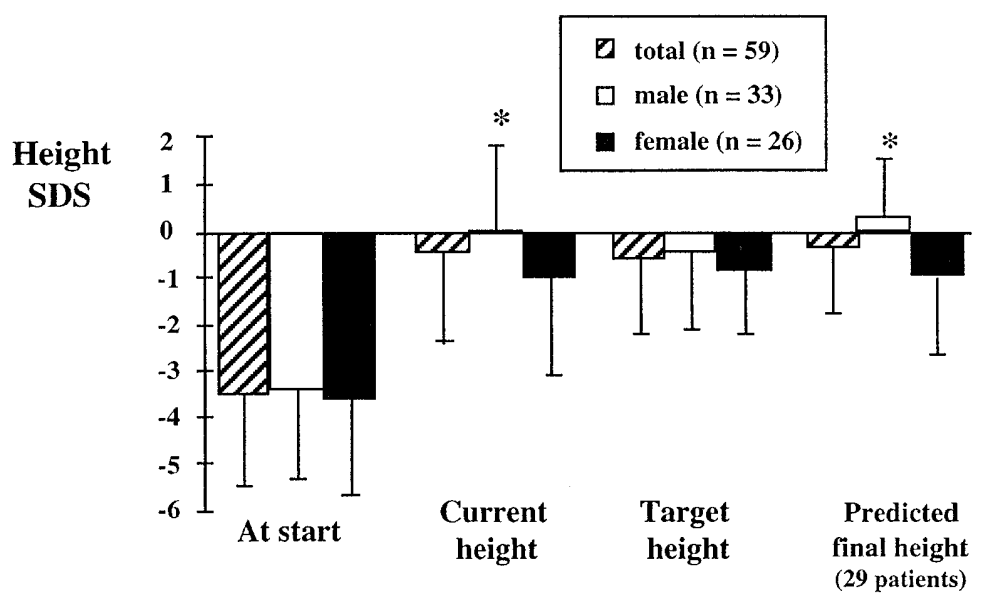

reports concerned a very limited number of patients with quite heterogeneous ages at initiation of therapy.

Our study extends these findings by analyzing patients who were younger than 1 year at the start of treatment and allows, in a larger group of patients, the analysis of predictive factors. Growth retardation at diagnosis was inversely correlated with total catch-up growth, a finding rarely reproduced in published series of older patients (14). This correlation persisted after exclusion of patients with initially normal height SDS and was due to a predictive effect on growth both during the first year of treatment and during further follow-up. In our multivariate analysis, first year catch-up growth was predictive of total catch-up growth, not surprisingly since it represents $63 \pm 45 \%$ of total catch-up. However, no correlation between first year catch-up growth and further changes in height SDS was found, underlining
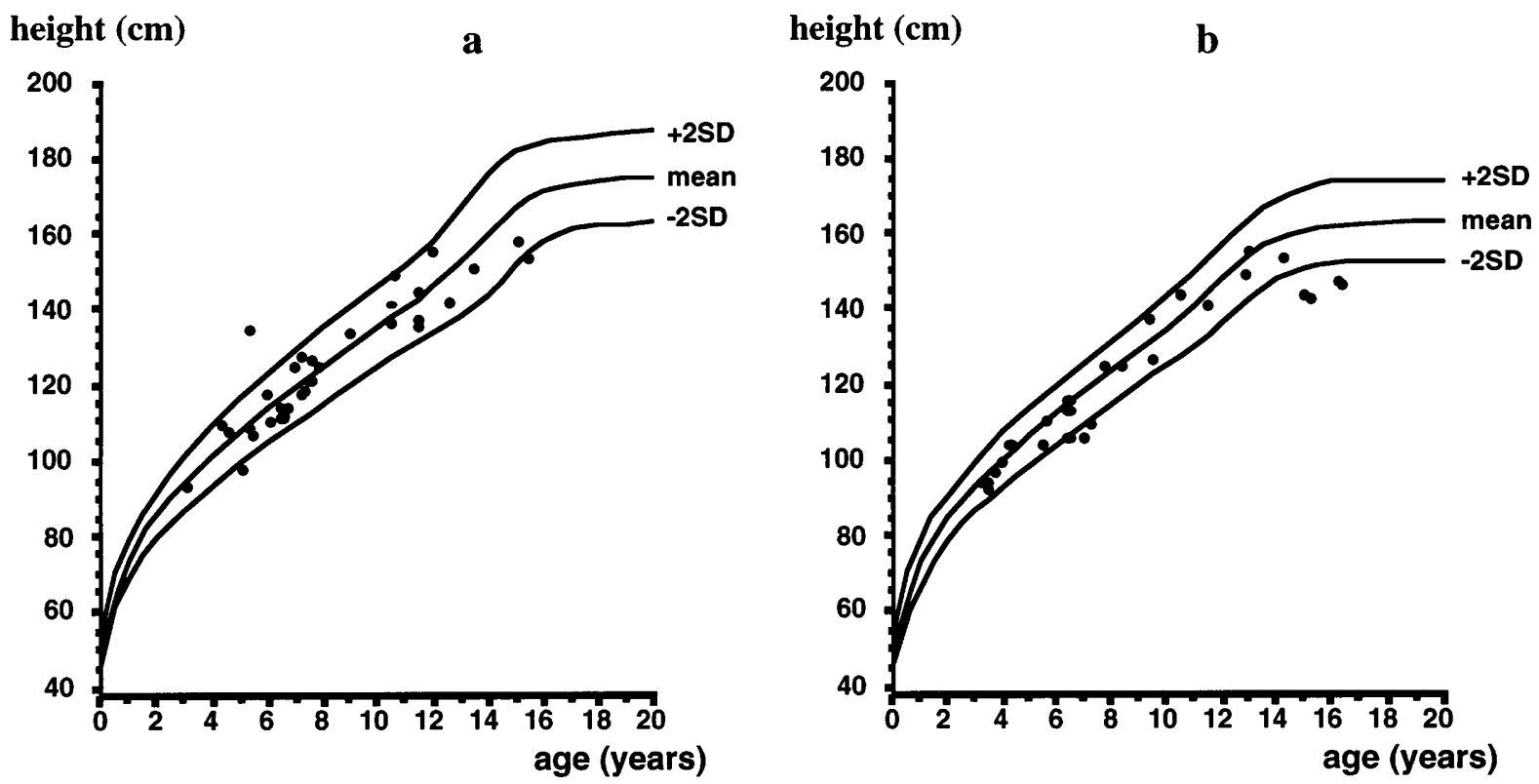

Figure 4 Current heights of 33 boys (a) and 26 girls (b) represented in the French references curves (15). 
the difficulty in identifying 'responders' to GH treatment on the basis of the first year's result (3). Patients with early and severe growth retardation therefore constitute the group of patients in whom GH treatment is the most effective and further research should aim at identifying the mechanisms of this unique sensitivity to $\mathrm{GH}$ and at attaining similar results in other patients.

BA remained significantly retarded after a mean of 8 years of therapy, suggesting that these substitutive doses allowed catch-up growth without exaggerated bone maturation. Moreover, since many of these patients have gonadotropin deficiency, they are expected to have a delayed BA around or a few years before the normal age of onset of puberty.

In conclusion, conventional doses of $\mathrm{GH}$ allow a normalization of height in patients with early GHD and treatment. The frequency of neonatal manifestations with delayed diagnosis underlines the importance of early recognition and diagnosis of GHD. Further studies should aim at reproducing such favorable results in older age groups.

\section{Acknowledgements}

The authors thank the pediatric endocrinologists who collected the clinical data and contributed to their validation: Profs Boudaillez, Chatelain, Czernichow, David, Freycon, Girard, Lecornu, Limal, Malpuech, Nivot, Pierson, Ponte, Rappaport, Raybaud and Rochiccioli and Drs Cabrol, Despert, Kessler, Koblinski, Kurtz, Lelouch, Sibille and Soskin. The authors would like to thank E Huet for secretarial assistance.

\section{References}

1 Price DA \& Ranke MB. Final height following growth hormone treatment. In Progress in Growth Hormone Therapy - 5 Years of KIGS, pp 129-144. Eds MB Ranke \& R Gunnarson. Mannheim: J \& J Verlag, 1994.

2 Blethen SL, Baptista J. Kuntze J, Foley T, Lafranchi S \& Johanson A. Adult height in growth hormone-deficient children treated with biosynthetic GH. Journal of Clinical Endocrinology and Metabolism $199782418-420$.

3 Coste J, Letrait M \& Carel JC. Long term results of growth hormone treatment in short stature children: a population register-based study. British Medical Journal 1997315 708-713.

4 Blethen SL, Compton P, Lippe BM, Rosenfeld RG, August GP \& Johanson A. Factors predicting the response to growth hormone therapy in prepubertal children with GH deficiency. Journal of Clinical Endocrinology and Metabolism 199376 574-579.

5 Maes M, Lindberg A, Price DA, Albertsson-Wikland K \& Ranke MB. Long-term growth response to growth hormone therapy in prepubertal children with idiopathic growth hormone deficiency: analysis of the Kabi International Growth Study. Kabi Internationa Growth Study Report 199411 15-26.

6 Wit JM, Kamp GA \& Rikken B. Spontaneous growth and response to growth hormone treatment in children with growth hormone deficiency and idiopathic short stature. Pediatric Research 199639 295-302.

7 Job JC. Early diagnosis and early treatment of growth hormone deficiency. Hormone Research 198931 149-152.
8 Vanderschueren-Lodeweyckx M, Van Den Broeck J, Wolter R \& Malraux P. Early initiation of growth hormone treatment: influence on final height. Acta Paediatrica Scandinavica 1987 337 (Suppl) 4-11.

9 Joss E, Zuppinger K, Schwarz HP \& Roten H. Final height of patients with pituitary growth failure and changes in growth variables after long term hormonal therapy. Pediatric Research $198317676-679$.

10 Mugnier E, Ployard F, Roy MP, Fermanian J \& Rappaport R. Résultats du traitement par l'hormone de croissance humaine chez les enfants insuffisants hypophysaires âgés de moins de 7 ans. Archives Françaises de Pédiatrie 198542 671-676.

11 Josefsberg Z, Bauman B, Pertzelan A \& Laron Z. Greater efficiency of human growth hormone therapy in children below five years of age with growth hormone deficiency. Hormone Research 198727 126-133.

12 Arrigo T, De Luca F \& Bernasconi S. Catch-up growth and height prognosis in early treated children with congenital hypopituitarism. Hormone Research 199544 (Suppl 3) 26-31.

13 Rappaport R, Mugnier E \& Limoni C. A 5-year prospective study of growth hormone $(\mathrm{GH})$-deficient children treated with $\mathrm{GH}$ before the age of 3 years. Journal of Clinical Endocrinology and Metabolism. $199782452-456$.

14 Boersma B, Rikken B \& Wit JM. Catch-up growth in early treated patients with growth hormone deficiency. Archives of Disease in Childhood 199572 427-431.

15 Sempé M, Pedron G \& Roy-Pernot MP. Auxologie, Méthodes et Séquences. Paris: Théraplix, 1979.

16 Usher R \& MacLean F. Intrauterine growth of live-born Caucasian at sea levels: standards obtained from measurements in seven dimensions of infants born between 25 and 44 weeks of gestation. Journal of Pediatrics 196974 901-910.

17 Sempé P \& Sempé M. Croissance et Maturation Osseuse. Paris: Théraplix, 1971.

18 Greulich WW \& Pyle SI. Radiographic Atlas of Skeletal Development of the Hand and Wrist. New York: Stanford University Press, 1970.

19 Bayley N \& Pinneau SR. Tables for predicting adult height from skeletal age. Revised for use with the Greulich-Pyle hand standards. Journal of Pediatrics $195240423-441$.

20 Herber SM \& Milner RDG. Growth hormone deficiency presenting under age 2 years. Archives of Disease in Childhood $198459557-$ 560 .

21 De Luca F, Bernasconi S, Blandino A, Cavallo L \& Cisternino M. Auxological, clinical and neuroradiological findings in infants with early onset growth hormone deficiency. Acta Paediatrica Scandinavica $199584561-565$.

22 Dean HJ \& Friesen HG. Long-term growth of children with growth hormone deficiency and hypoglycemia. Journal of Pediatrics 1989 115 598-600.

23 Cornblath H \& Schwartz R. Hypoglycemia in the neonate. In: Disorders of Carbohydrate Metabolism in Infancy, pp 177-180. Eds H Cornblath \& R Schwartz. Philadelphia: WB Saunders, 1976.

24 Wit JM \& Van Unen H. Growth of infants with neonatal growth hormone deficiency. Archives of Disease in Childhood 199267 920-924.

25 Chatelain P. Dramatic early postnatal growth failure in children with early onset growth hormone deficiency. Acta Paediatrica Scandinavica 1991379 (Suppl) 100-102.

26 Gluckman PD, Gunn AJ \& Wray A. Congenital idiopathic growth hormone deficiency associated with prenatal and early postnatal growth failure. Journal of Pediatrics 1992121 920-923.

27 De Luca F, Maghnie M, Arrigo T, Lombardo F, Messina MF \& Bernasconi S. Final height outcome of growth hormone-deficient patients treated since less than five years of age. Acta Paediatrica $1996851167-1171$.

Received 14 July 1998

Accepted 28 September 1998 